\title{
Cranio-facial Dysostosis in a Dorset Family
}

\author{
DAVID G. VULLIAMY and PETER A. NORMANDALE \\ From the West Dorset Medical Society for Postgraduate Education and Research, Dorset County Hospital, Dorchester
}

Crouzon (1912), whose name has been given to the combination of developmental anomalies which he described as hereditary cranio-facial dysostosis, presented his first two cases to the Société Médicale des Hôpitals de Paris. The patients, a mother aged 29 years and her son aged $2 \frac{1}{2}$ years, had a malformation of the cranial vault consisting of protrusion in the region of the bregma, widening transversely, and shortening antero-posteriorly. The outstanding facial features were bilateral exophthalmos, a beaked nose, a hypoplastic maxilla, and a narrow arched palate.

Descriptions of other similar cases followed (e.g. Debré and Petot, 1927), and the skull malformation was shown to be due to premature fusion of cranial sutures. A detailed review of all published papers on the subject was undertaken by Atkinson (1937) who was able to find accounts of 86 cases at that time. Many others have since been added from all parts of the world.

Unfortunately the published material on the subject tends to be confused by the other forms of craniosynostosis, either occurring alone or with associated malformations. Terminology is sometimes descriptive of the head shape and this depends upon which sutures unite early. The long narrow head caused by premature fusion of the sagittal suture alone is given the name of dolicocephaly or scaphocephaly (resembling the keel of an upturned boat). When the coronal sutures are mainly affected the skull is short antero-posteriorly and the term brachycephaly is used. Acrocephaly describes the type which forms a pointed prominence in the region of the bregma.

Where there is more widespread fusion including coronal, sagittal, and sometimes lambdoid sutures, failure to grow normally in lateral and anteroposterior directions results in the tall cranium with small capacity known as oxycephaly. Here, compression of the growing brain and exophthalmos due to pressure on the orbital roof are likely to occur.

Other types have been classified either on the

Received November 22, 1965. basis of their associated congenital anomalies or have been given eponyms. In Apert's disease (acrocephalosyndactyly) there is a high pointed skull due to early fusion of coronal and usually part of the sagittal and lambdoid sutures, in association with variable degrees of syndactyly (Park and Powers, 1920). It is the associated malformation rather than the precise extent of the craniosynostosis which is the guiding factor in differential diagnosis between Apert's disease and Crouzon's disease, the facial features of the latter being distinctive. From the description of Crouzon's original cases it seems probable that there was synostosis mainly of the coronal sutures, the protrusion in the region of the anterior fontanelle being due to the fact that fusion was latest at their upper ends, leaving an area of compensatory dilatation to be filled by the expanding brain. In other reported examples with similar facial anomalies a much earlier and more extensive craniosynostosis has been present, for example that described by Flippen (1950) where, at 4 years, only the spheno-occipital sutures remained unfused. Shiller (1959) has reported a family in which the presenting case had premature fusion of all the cranial sutures early in the first year of life.

The amount of disability is also variable. Some of these patients have developed disturbances of visual function varying from a divergent squint to complete optic atrophy. Some have been seriously mentally defective, though proper studies to show whether this is inborn or the result of progressive deterioration are lacking. Other manifestations of increased intracranial pressure such as headaches and fits have been surprisingly seldom mentioned in spite of the supposed radiological signs of pressure.

Although the original cases of Crouzon were named hereditary cranio-facial dysostosis, many instances have been described without a positive family history. In Atkinson's series (1937) 28 out of 86 were not apparently hereditary. When inherited, there is always evidence of transmission from parents to children, about half of whom are affected, which pattern points conclusively to a Mendelian dominant mode. Sporadic cases 
may well be due to fresh mutations of the same dominant gene.

The family described here bears out this mode of inheritance and demonstrates the fact that the condition can be compatible with an average lifespan and surprisingly little disability.

\section{Case Reports}

IV.6 (family tree, Fig. 1). This boy was born on November 1, 1954. Dr. T. B. L. Bryan drew attention to him at the age of 2 on account of his odd appearance. His mother was not very concerned about this for, as she explained, the facial appearance could be accounted for by his 'taking after his father' and was similar to that of several other members of the family.

No abnormality of the skull or face was recorded in the newborn period. He walked unaided by 14 months, but was slow to develop speech and when seen at 2 years could only manage a few single words.

The face was characteristic of cranio-facial dysostosis, showing moderate exophthalmos and a short underdeveloped maxilla (Fig 2a). The cranial vault was long antero-posteriorly and the shape was mainly remarkable for the protrusion at the site of the anterior fontanelle which was still patent and displaced somewhat forwards. About 2 in. $(5 \mathrm{~cm}$.) behind this in the mid-line was a rounded defect of the bone about 0.75 in. $(2 \mathrm{~cm}$.) in diameter through which protruded a soft pulsating swelling (a small meningocele).

Radiographs of the skull (Fig. 2b) showed fusion of all sutures except the lower half of the coronal and the occipito-temporal sutures. The vault was abnormally long in its antero-posterior diameter with deepening of the posterior basal fossa, and there was marked peaking of the vertex in the region of the anterior fontanelle. Convolutional markings were prominent and the pituitary fossa was slightly enlarged.

There was no apparent defect of vision on simple tests and both optic fundi were normal.

Neurosurgical advice was sought, but in view of the age of the patient ( 2 years 3 months), and the absence of symptoms, no operation was recommended. The patient was therefore kept under review and further investigations carried out in the ensuing years. Radiographs of the skull at 5 years showed complete fusion of all sutures (Fig. 2c). Ophthalmological tests showed divergence of the left eye for the first time at the age of 7 years, but visual acuity had remained normal. Optic discs showed very slightly increased pallor. As a first step to improve the facial appearance and exophthalmos, plastic surgery was undertaken at 8 years (Mr. J. E. Laing) by introduction of two pieces of rib cartilage to the front of each maxilla (Fig. 2d).

Chromosome studies on blood culture from the patient and his father (III.8, Fig. 1) were carried out at Guy's Hospital Paediatric Research Unit through the help of Professor P. Polani : they showed no abnormality.

Educational attainment. Owing to a combination of bad social circumstances at home with an intelligence quotient of 67 (Stanford Binet) and a poor record at his primary school, he was admitted to a residential school for educationally subnormal children at 8 years. Here his rate of progress increased and learning ability improved. There is no sign of any progressive mental deterioration, and his low IQ can as well be attributed to

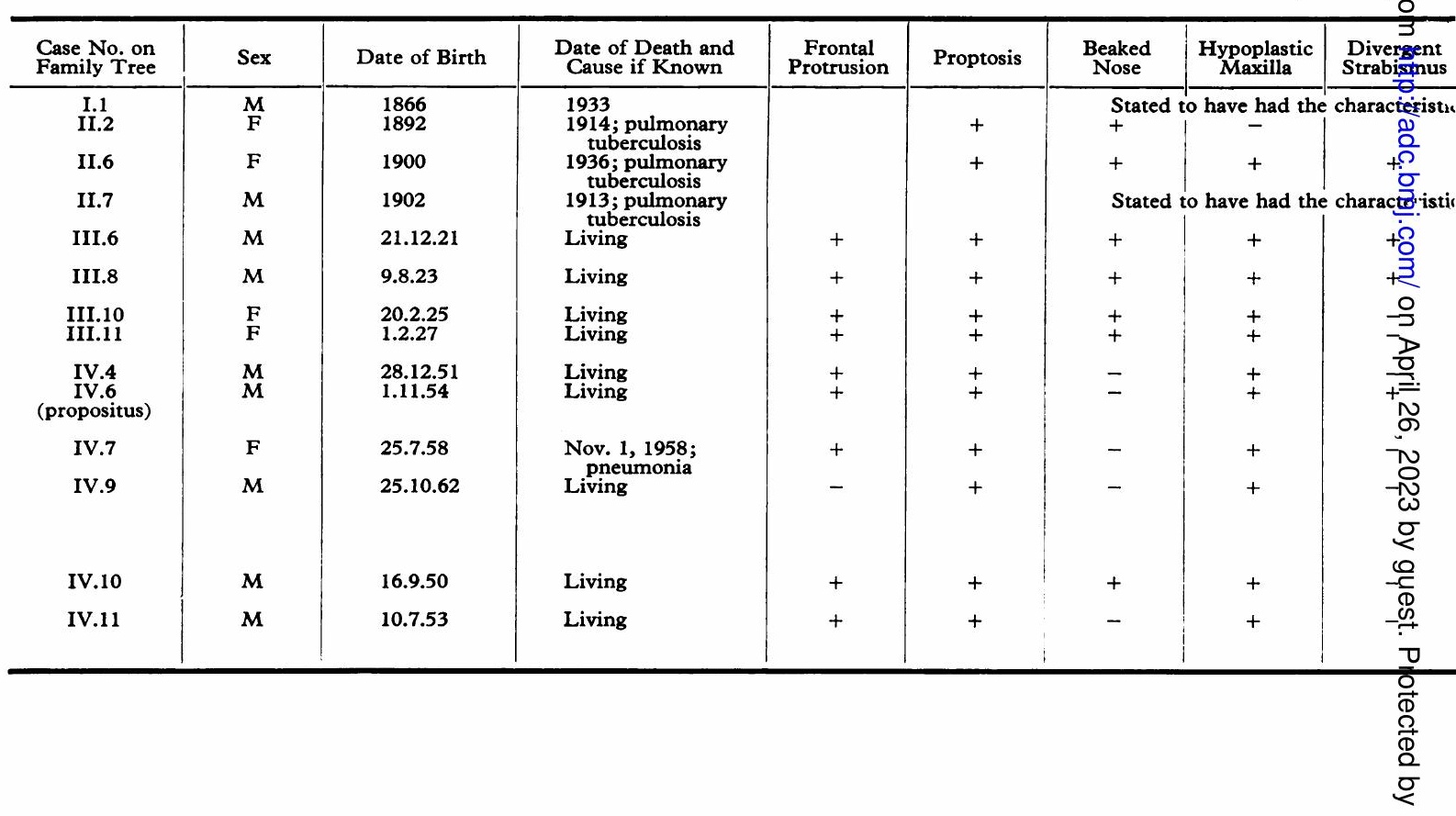




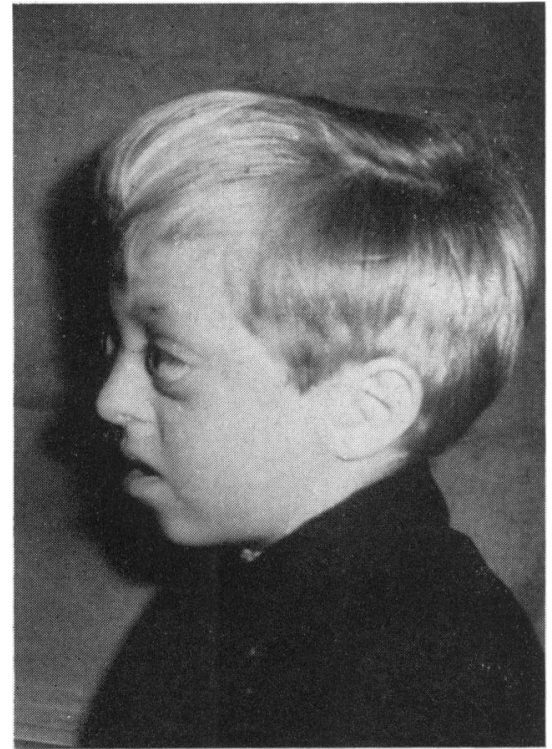

FIG. 2a.-IV.6 aged 3 years.

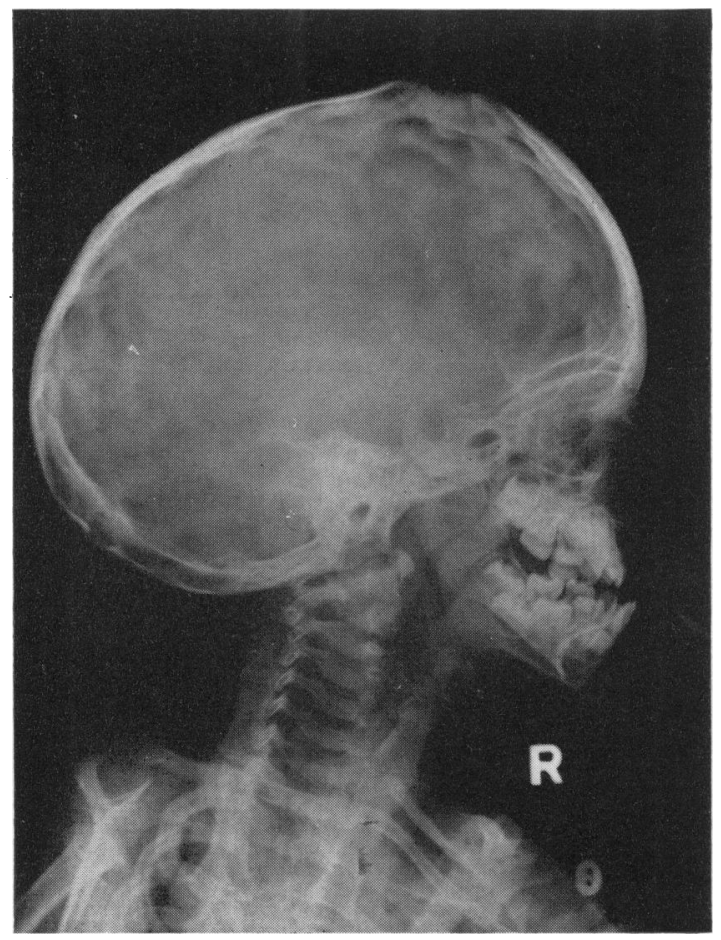

Fig. 2b.-IV.6. Skull at 2 years and 3 months, showing the peak at the bregma and partial union of sutures.

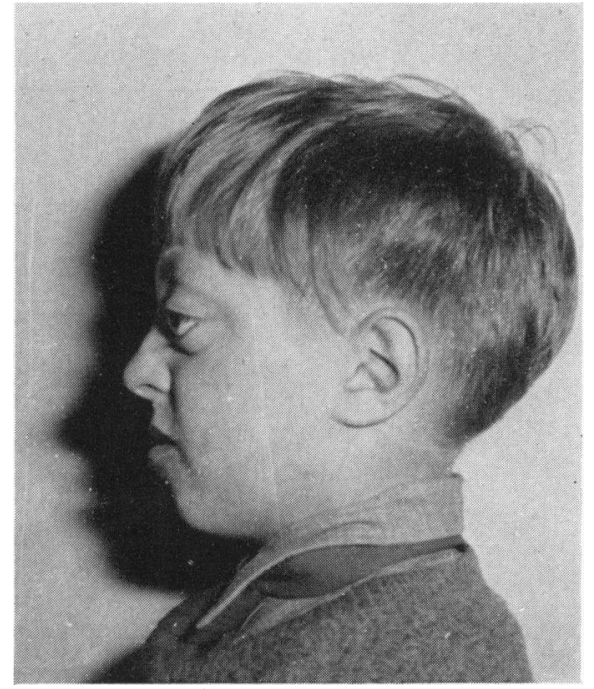

Fig. 2d.-IV.6 at 8 years.

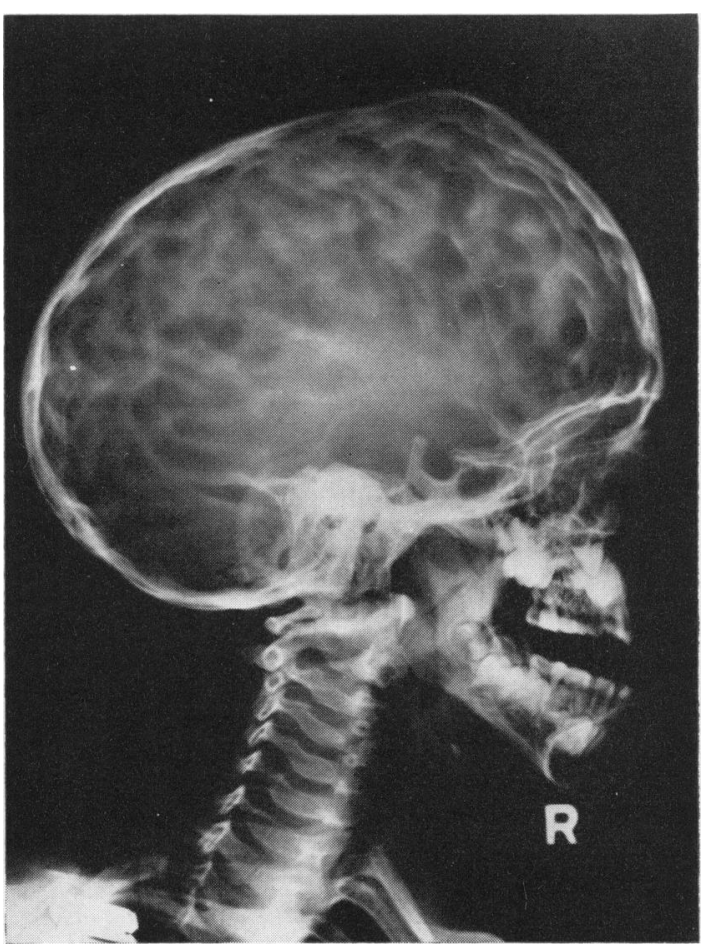

FIG. 2c.-IV.6. Skull at 5 years, showing complete union of sutures and excessive convolutional markings. 


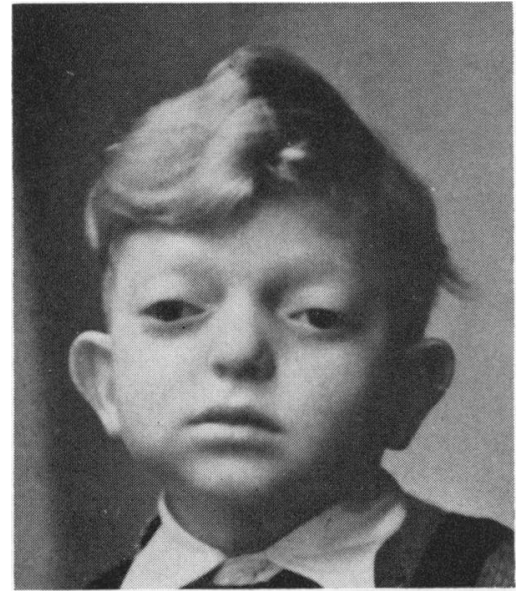

FIG. 3a.-IV.4.

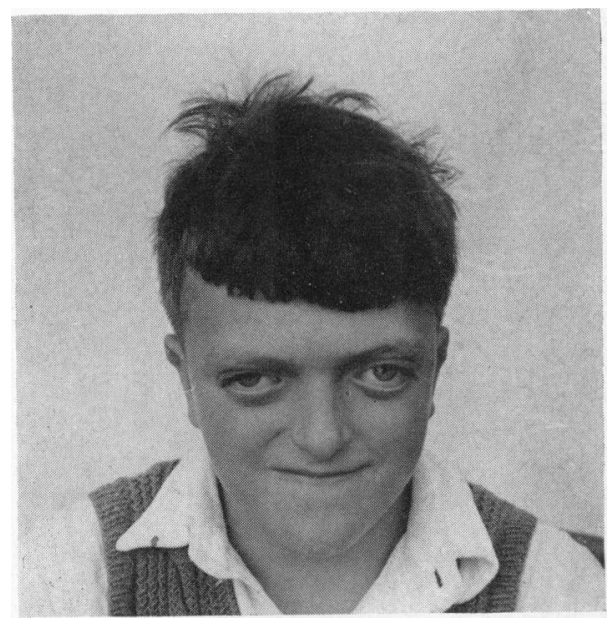

FIG. 3b.-IV.10.

Fig. 3d.-IV.11. Skull radiograph at 4 years showing almost complete union of sutures.

sutures except at their upper ends. A Griffiths developmental test at 11 months gave a general Quotient of 82 .

In view of the extent of the synostosis and the fact that it had progressed so far at an early age, it was decided that operation to prevent brain compression and damage was advisable. The baby was thus referred to Mr. K. Till at the Neurosurgical Department, The Hospital for Sick Children, Great Ormond Street, London, where further investigation showed evidence of slightly raised

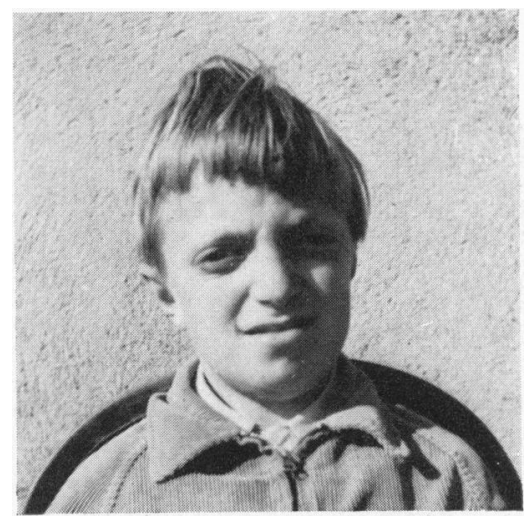

Fig. 3c. $-I V .11$.

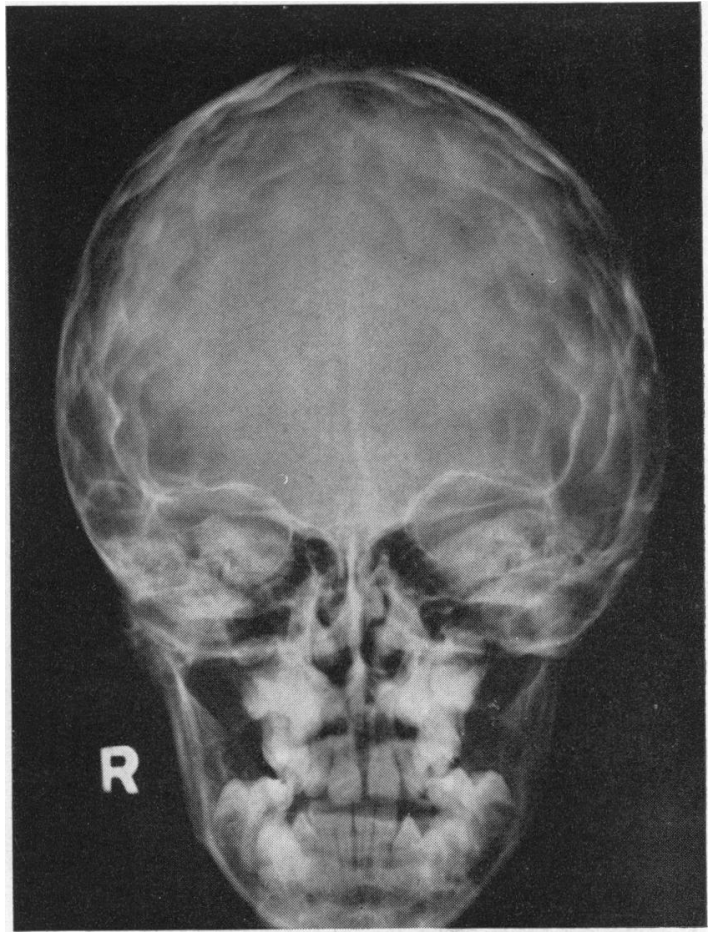

intracranial pressure with possible early papilloedema. Skull radiographs at 2 years showed almost complete union of sutures (Fig. 6c).

Craniotomy was therefore undertaken on the left side, a bone flap being raised. The operation was repeated on the right side 3 months later (Fig. $6 \mathrm{~d}$ ), the original bone flap having become raised indicating a continued rise of intracranial pressure.

The subsequent course of development remains to be followed. 


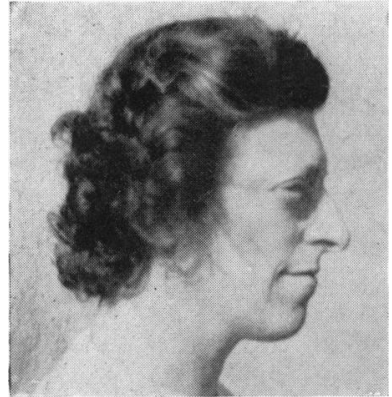

FIG. 4a.-III.10.

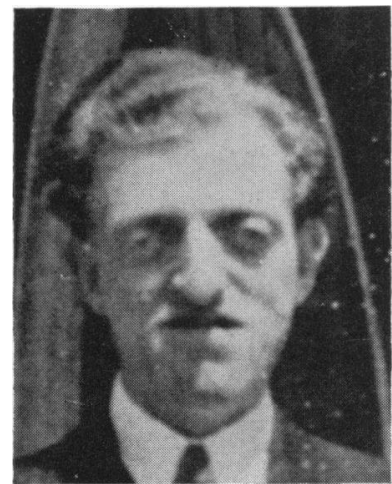

Fig. 4d.-III.6.

FIG. 4e.-III.8. Skull radiograph showing union of sutures and hypoplasia of maxilla.

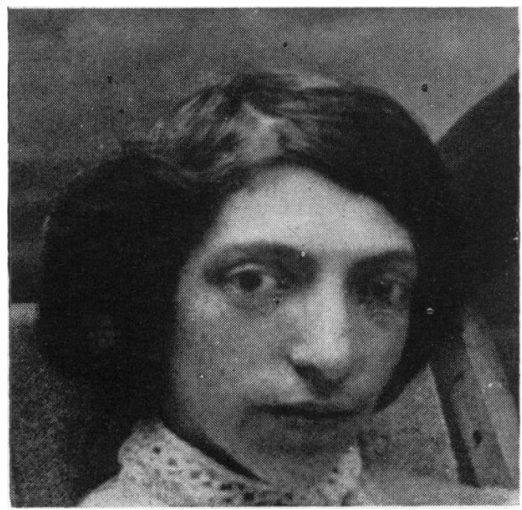

FIG. 5a.-II.2.
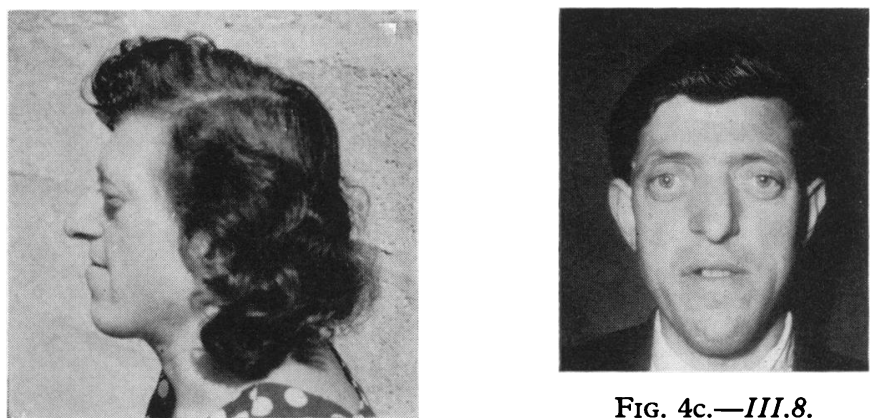

FIG. 4c.-III.8.

FIG. 4b.-III.11.
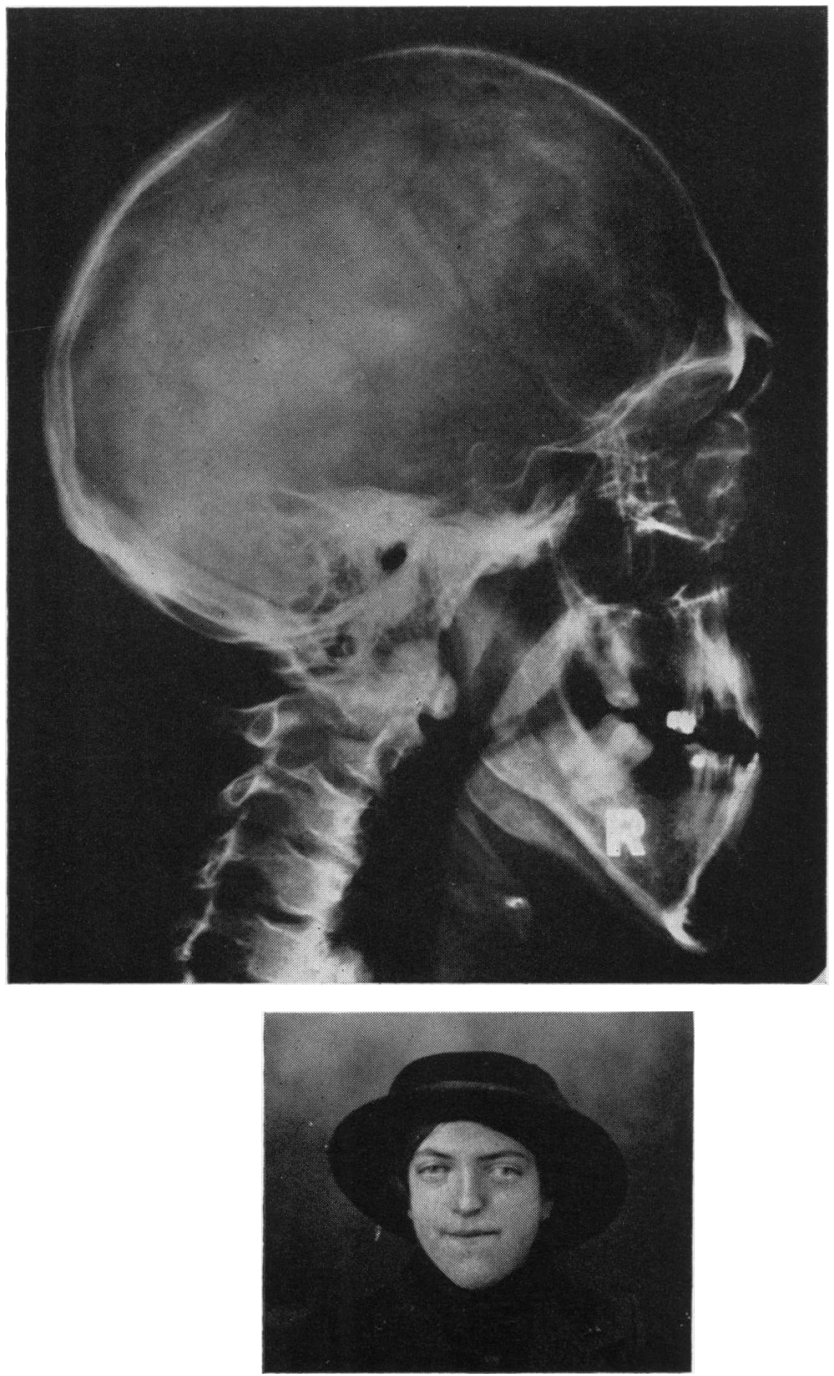

FIG. 5b.-II.6. 


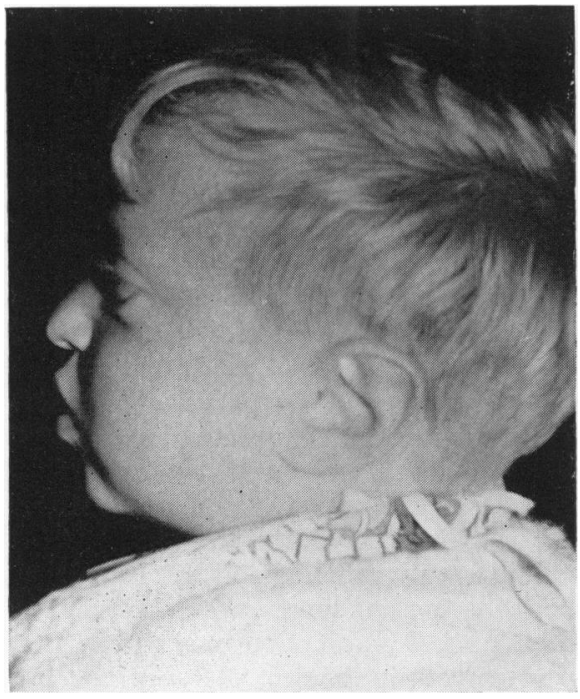

FIG. 6a.-IV.9, aged 1 year.

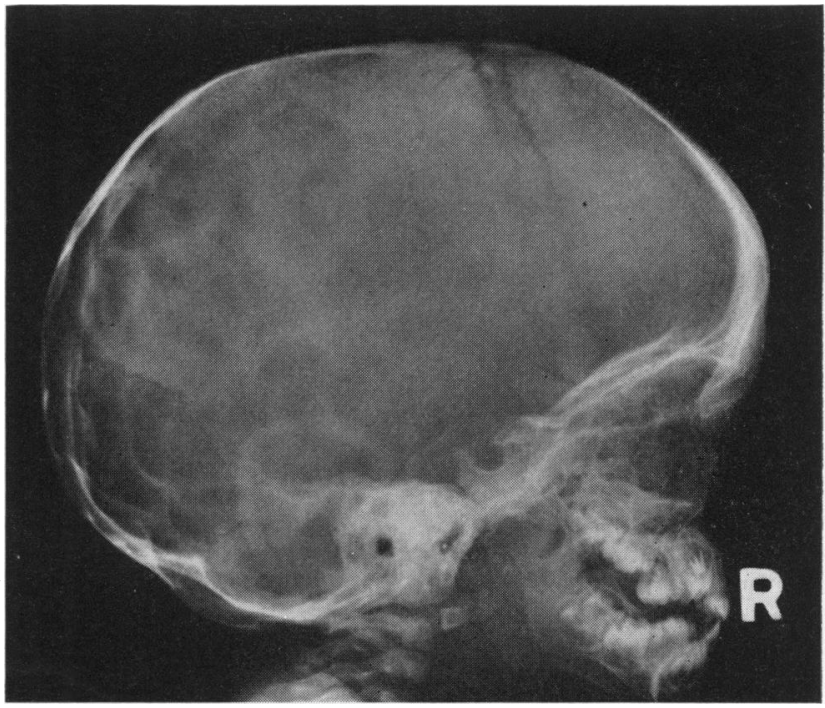

Fig. 6b.-IV.9. Skull radiograph at 11 months showing the beginning of early union of coronal sutures.

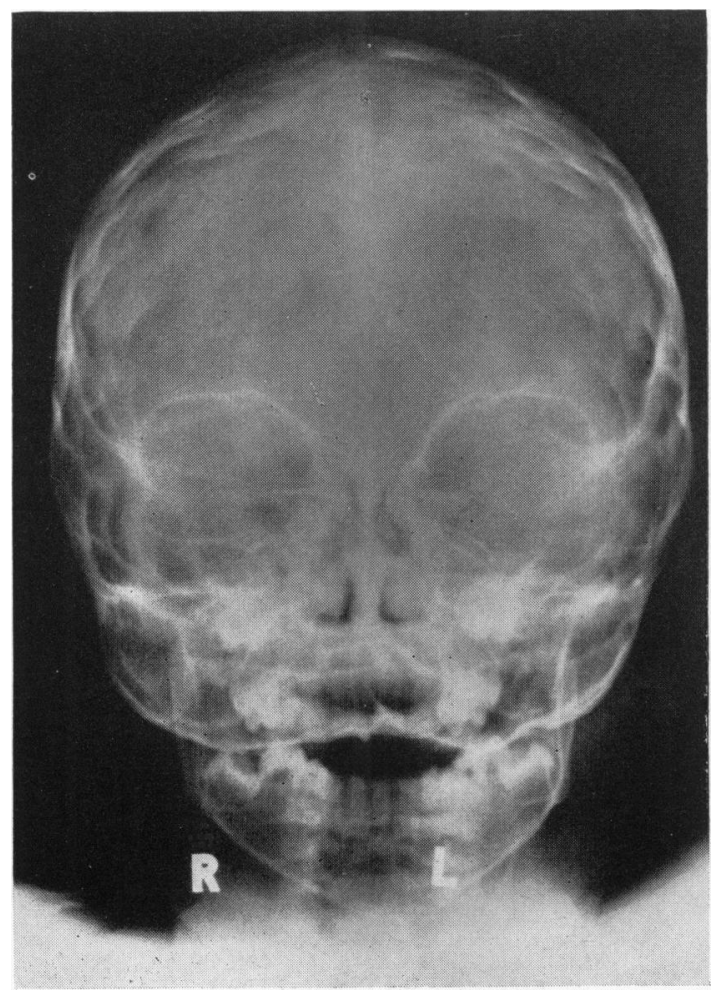

Fig. 6c.-IV.9. Skull radiograph at 2 years showing almost complete union of sutures before operation.

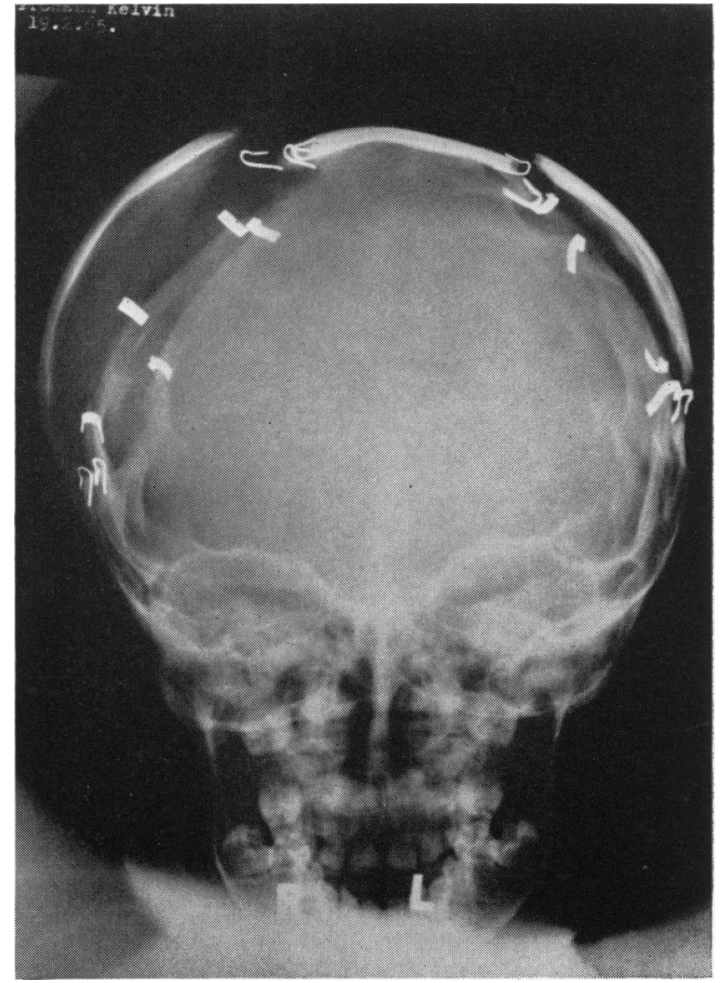

Fig. 6d.-IV.9. Skull radiograph at 2 years 4 months after operation showing raised bone flaps. 


\section{Discussion}

The 14 affected members of this family whom we have been able to trace with certainty are sufficient to confirm the dominant mode of inheritance of cranio-facial dysostosis. 9 were males and 5 were females. Family photographs were rare in rural communities of this kind before 1900 , so it has not been possible to obtain reliable evidence about generations earlier than that of the great-grandfather of our presenting case.

The life-span of those members of the family born in the early years of the century was shortened by pulmonary tuberculosis, but susceptibility was no greater in those with cranio-facial dysostosis than in those without it. The amount of disability directly attributable to the malformation in this particular family is small up to now. Perhaps their standards have not been set high, and with the diminishing isolation of the rural community in which they live, they may become less tolerant of their unusual endowment.

The proptosis and divergence of the eyes has been sufficient to cause a problem in one member of the family only (IV.6), but in none is there evidence of optic atrophy or severe loss of vision so far. The death of IV.7 was not attributable to the disorder and there were associated more serious abnormalities.

There is no certain evidence that the craniosynostosis itself has been responsible for impairment of intelligence. IV.6 goes to a school for educationally subnormal and maladjusted children, and his IQ has been rated at 67 at 8 years of age, but it is doubtful if this can be attributed to his cranio-facial dysostosis, taking into consideration the fact that his mother (who does not suffer from the disease) has a level of intelligence greatly below average. A similar situation is seen in other members of the family. For example, IV.10 had an IQ of 86, while an unaffected cousin was rated as having an IQ of 80 .

The question of whether operation to prevent increasing intracranial pressure is indicated in any individual case may be very difficult to answer. According to most neurosurgical opinions, if it is to be done at all it should be done in the first year of life when brain growth is at its maximum.

Pinkerton and Pinkerton (1952) give the following indications: (1) progressive exophthalmos; (2) progressive optic atrophy; (3) progressive mental deficiency; (4) simple increased intracranial pressure (without any of the above): (5) digital impressions on the skull radiograph.

The second, third, and fourth of these indications are surely valueless, for by the time they are established it is likely to be too late. Digital impressions on skull radiographs in childhood are present in normal children to a variable extent, and cannot be used alone as a guide.

Whether or not impairment of cerebral function will develop depends upon the extent of the craniosynostosis and the age at which the process of synostosis begins. In a case where obvious cranial deformity and extensive union of sutures is present at birth, as in the case of Shiller (1959), early operation is clearly advisable. On the other hand, where a reasonable proportion of the total extent of the sutures remains unclosed for two or three years as has happened in most members of this family, it is probable that brain development may be unimpaired and surgical measures necessary only for cosmetic reasons or for the exophthalmos itself.

Careful clinical and radiological assessment of each case from the earliest stage is essential, and as in IV.9 of this series, if union of coronal and sagittal sutures is seen to occur in the first year, operation to prevent possible increased intracranial tension should be undertaken.

\section{Summary}

A family, 14 members of which are known to have been affected by cranio-facial dysostosis, is described. The dominant mode of inheritance is demonstrated. Chromosome abnormalities were absent in the 2 cases tested. Only the youngest affected member of the family was submitted to craniotomy. The course of the disorder and the indications for treatment are discussed.

We should like to acknowledge the help of the following: Dr. T. B. L. Bryan, Dr. P. Fleury, and some members of the affected family for case findings. Dr. J. F. Rose for most of the radiographs and reports thereon. The Photographic Department of the Royal Society of Medicine, and the Illustration Department of the Hospital for Sick Children, Great Ormond Street, for reproduction of some of the photographs.

\section{REFERENCES}

Atkinson, F. R. B. (1937). Hereditary cranio-facial dysostosis, or Crouzon's disease. Med. Press, 195, 118.

Crouzon, O. (1912). Dysostose cranio-faciale héréditaire. Bull. Mém. Soc. méd. Hôp. Paris, 33, 545.

Debré, R., and Petot, C. (1927). Une famille de sujets atteints de dysostose cranio-faciale. Arch. Méd. Enf., 30, 274.

Flippen, J. H., Jr. (1950). Cranio-facial dysostosis of Crouzon. Report of a case in which the malformation occurred in 4 generations. Pediatrics, 5, 90.

Park, E. A., and Powers, G. F. (1920). Acrocephaly and scaphocephaly with symmetrically distributed malformations of the extremities. A study of the so-called "acrocephalosyndactylism". Amer. F. Dis. Child., 20, 235.

Pinkerton, E. D., and Pinkerton, F. J. (1952). Hereditary craniofacial dysplasia. Amer. F. Ophthal., 35, 500.

Shiller, J. G. (1959). Cranio-facial dysostosis of Crouzon. A case report and pedigree with emphasis on heredity. Pediatrics, 23, 107. 